\title{
Behavior of Double Fish Plate Connector between Steel Plate Shear Wall Structure and Steel Frame
}

\author{
Guochang $\mathrm{LI}^{1}$, Zengmei QIU ${ }^{2}$ and Zhijian $\mathrm{YANG}^{3 *}$ \\ ${ }^{1}$ Professor, School of Civil Engineering, Shenyang Jianzhu University \\ ${ }^{2}$ PhD candidate, School of Civil Engineering, Shenyang Jianzhu University \\ ${ }^{3}$ PhD, School of Civil Engineering, Shenyang Jianzhu University \\ Corresponding author's e-mail: faemail@163.com
}

\begin{abstract}
This paper mainly researched the behavior of double fish plate connector between steel plate shear wall structure and steel frame. Four single fish plate connectors and four double fish plate connectors were tested under monotonic and cyclic loading. The hysteretic curves, skeleton curves, stiffness degradation curve and ductility coefficient were considered to study the behavior of two connections. Results showed that the behavior of double fish plate connector between steel plate shear walls and steel frame was better than single fish plate connector. Double fish plate connectors had higher bearing capacity, slower stiffness degradation, better ductility and better energy dissipation capacity. Constraint effect of steel plate shear walls became stronger, and the out-of-plane buckling failure of steel plate shear walls was delayed. Therefore, the double fish plate connectors could improve the behavior of connection between steel plate shear walls and steel frame, and provide a reference for engineering application.
\end{abstract}

\section{KEYWORDS}

Double fish plate connectors; steel frame; steel plate shear walls; monotonic loading test; cyclic loading test

\section{INTRODUCTION}

Steel plate shear walls (SPSWs) are based on steel frame, and the system consist of an embedded steel plate and boundary elements. The main function of SPSWs is to resist interlaminar shear and bending moment which are produced by wind load and seismic load, and to control the structural horizontal displacement effectively. SPSWs have been accepted due to the characteristic of constructing convenience, materials saving, good ductility, anti-seismic capability and stable hysteretic behavior, and many scholars have made large and deep research about its behaviors.

Researches of SPSWs were mainly focused on different forms of shear walls, shear bearing capacity, hysteresis behavior and behaviors of connecting to other parts. Mimura used simplified model to study the bearing capacity of SPSWs, and proposed the hysteretic models of steel sheet (Mimura 1977). Elgaaly studied SPSWs of 10 specimens of single-story and third-span frame, and put forward a new method to forecast the hysteretic behavior of SPSWs (Elgaaly 1992). 
Wang studied the hysteretic behavior of thin steel plate shear wall by finite element analysis (Wang 2015).

Many scholars have studied SPSWs with or without stiffening rib. Takahashi studied behavior of SPSWs with stiffening rib through experiment and finite element analysis (Takahashi 1973). Thorburn studied behavior of SPSWs without stiffening rib (Thorburn 1983). Then Driver studied behavior of SPSWs without stiffening rib by using specimens of single-story and fourthspan frame. Results showed that specimens had better ductility and energy dissipation capacity (Driver 1998). Chen carried out an experiment to study the cross stiffening rib steel plate shear walls (Chen 2004).

In order to improve the behavior of SPSWs, researchers have studied different forms of SPSWs. Roberts studied SPSWs with circular holes under cyclic loading test, and got the reduction factor of stiffness and ultimate bearing capacity (Roberts 1991). Hitaka proposed a new type of SPSWs with silts, and the test results showed when the high-thickness ratio of batten was less than 20 and the displacement between two layers of specimens was 3\%, the bearing capacity and stiffness were no obvious degradation phenomenon (Hitaka 2003). Guo studied buckling restrained SPSWs under cyclic loading test, which showed that this form of SPSWs could prevent out-of-plane deformation of steel plate and improve the energy dissipation capacity significantly (Guo 2009). Maurya put forward a new form of ring-shaped SPSWs, which had good seismic behavior and high stiffness (Maurya 2013).

In recently, some researches began to study the connection between SPSWs and other parts. Kulak studied SPSWs of beams and columns connected by bolts, which showed that the energy dissipation capacity of SPSWs connected by rigid connection was better than SPSWs connected by hinged connection (Kulak 1985). Xie and Hao studied the behavior of semi-rigid connection steel frame with unstiffened SPSWs (Xie 2010, Hao 2011). Guo put forward four-angle connection to connect steel frame and SPSWs, and results showed that the behavior of new connection was better (Guo 2013).

It can be seen from above researches, the study about behavior of connection between steel plate shear wall structure and steel frame was few. Single fish plate connector has been widely used in engineering, while this connection is easy to be out-of-plane buckling. Therefore, a new type connection of double fish plate connection was proposed and tested in this paper.

\section{EXPERIMENTAL STUDY}

\section{Specimen design}

A total of 8 specimens were tested under monotonic and cyclic loading. Specimen size is shown in Table 1. SPD-1, SPD-2, SPW1, SPW-2 are SPSW specimens connected by traditional single fish plate connection, as shown in Figure 1(a), and DPD-1, DPD-2, DPW1, DPW-2 are SPSW specimens connected by double fish plate connection, as shown in Figure 1(b). SPD-1, SPD2, DPD-1, DPD-2 were loaded under monotonic loading, SPW-1, SPW-2, DPW-1, DPW-2 were loaded under cyclic loading. 
Table 1. Specimen size.

\begin{tabular}{ccccccc}
\hline $\begin{array}{c}\text { Specimen } \\
\text { number }\end{array}$ & $\begin{array}{c}\text { Length of } \\
\text { connection } \\
\text { plate }(\mathrm{mm})\end{array}$ & $\begin{array}{c}\text { Width of } \\
\text { connection } \\
\text { plate }(\mathrm{mm})\end{array}$ & $\begin{array}{c}\text { Thickness of } \\
\text { connection } \\
\text { plate }(\mathrm{mm})\end{array}$ & $\begin{array}{c}\text { Length of } \\
\text { SPSW } \\
(\mathrm{mm})\end{array}$ & $\begin{array}{c}\text { Width of } \\
\text { SPSW } \\
(\mathrm{mm})\end{array}$ & $\begin{array}{c}\text { Thickness of } \\
\text { SPSW } \\
(\mathrm{mm})\end{array}$ \\
\hline SPD-1 & 600 & 60 & 6 & 600 & 370 & 9 \\
SPD-2 & 600 & 60 & 6 & 600 & 370 & 9 \\
SPW-1 & 600 & 60 & 6 & 600 & 370 & 9 \\
SPW-2 & 600 & 60 & 6 & 600 & 370 & 9 \\
DPD-1 & 600 & 60 & 4 & 600 & 370 & 9 \\
DPD-2 & 600 & 60 & 4 & 600 & 370 & 9 \\
DPW-1 & 600 & 60 & 4 & 600 & 370 & 9 \\
DPW-2 & 600 & 60 & 4 & 600 & 370 & 9 \\
\hline
\end{tabular}

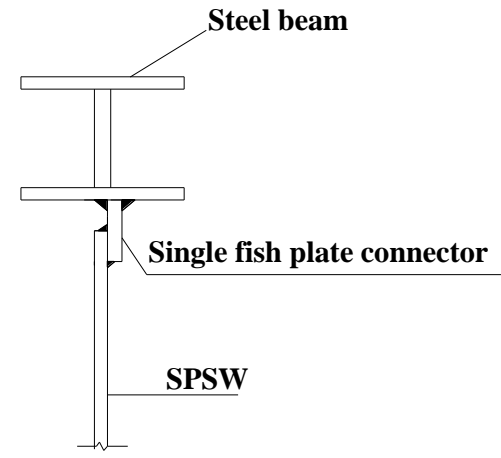

(a) Single fish plate connection

Figure 1. Two kinds of connections.

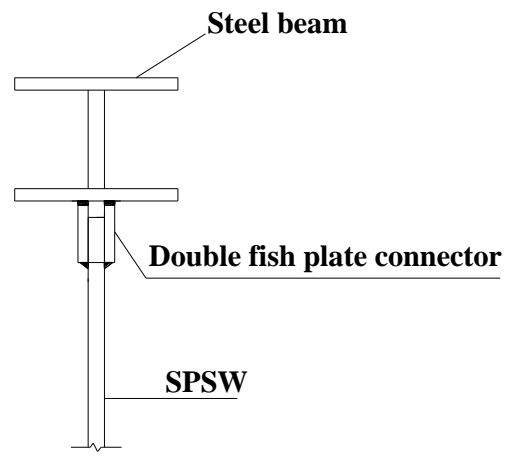

(b) Double fish plate connection

\section{Testing equipment}

According to the test bearing capacity requirement, a reaction frame $1200 \mathrm{kN}$ and MTS (hydraulic servo loading system) 250 actuator with a force capacity of $1500 \mathrm{kN}$ were used. Specimen was fixed by welding a pair of steel braces on both sides to prevent in-plane instability of specimen. On the perpendicular to the loading direction of specimen was restrained by a pair of steel braces to avoid out-of-plane instability. Testing equipment is shown in Figure 2.

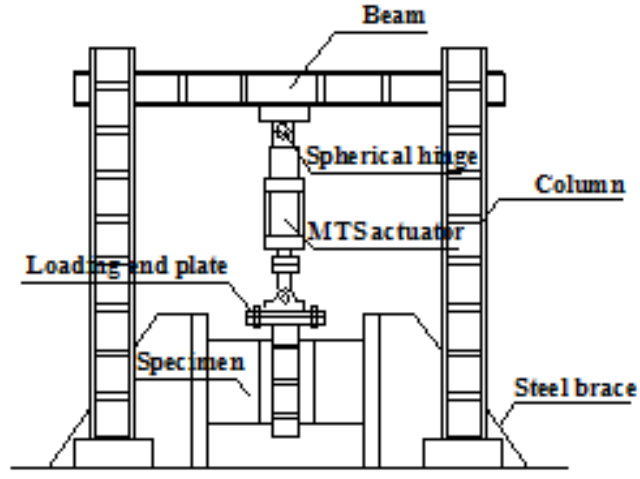

(a) Front view

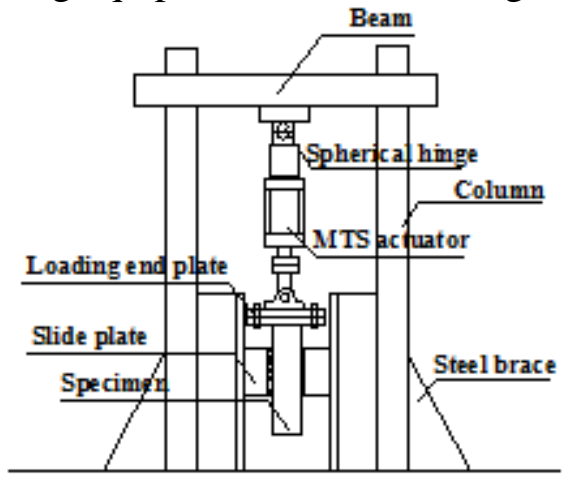

(b) Side view

Figure 2. Testing equipment. 


\section{Loading scheme}

Loading included preloading and formal loading. The preloading was conducted to check the reliability of the equipment and connection, and made sure the smooth progress of formal loading.

Monotonic loading test was controlled by load, and each load level was $10 \mathrm{kN}$. The test was not stopped until the load declined to $85 \%$ of the ultimate bearing capacity and the maximum bearing capacity during loading was defined as the ultimate bearing capacity. Cyclic loading test was controlled by displacement, and each load level was $2 \mathrm{~mm}$. As the specimen yielded, the displacement was obtained to be yielding displacement, and next load level was controlled by multiples of the yielding displacement, which looped 2 times. The test was not stopped until specimen appeared buckling failure or weld cracked.

\section{Experimental measurement}

During loading, stress changes of specimen at different locations were obtained by arranging strain rosettes. For specimens connected by single fish plate connectors, strain rosettes (S1-S6) were arranged on one side and near the place of welding between connectors and steel plate, as shown in Figure 3(a). For specimens connected by double fish plate connectors, strain rosettes (D1-D6, D1'-D6') were arranged on both sides, as shown in Figure 3(b). The above mentioned strain rosettes were arranged in the middle of fish plate connectors.

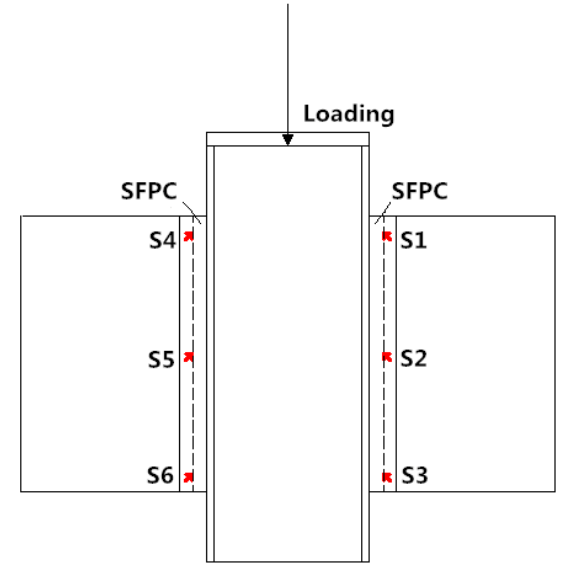

(a) Single fish plate connection

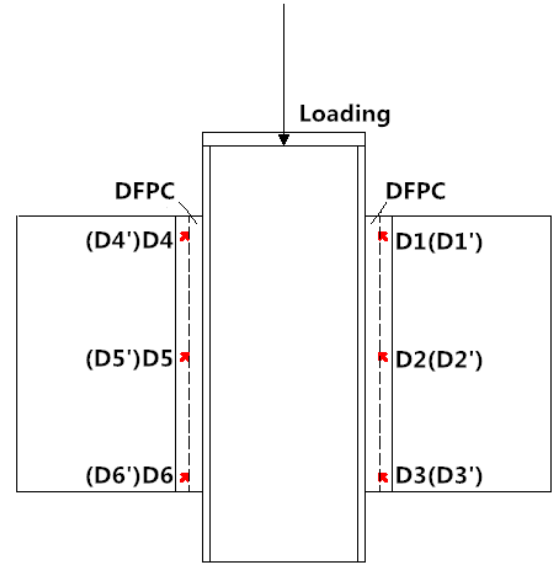

(b) Double fish plate connection

Figure 3. Strain rosettes of arrangement.

\section{Experimental phenomenon}

During the initiation of loading, specimens had no significant changes. Continued to load, strain value of strain rosette S1(D1) first reached yield strain, then strain values of strain rosette S4(D4) and S2(D2) reached yield point and specimen began to appear out-of-plane deformation. Continued to load, strain values of strain rosette S3(D3), S5(D5) and S6(D6) all reached yield point, finally, the test was stopped when specimen appeared buckling failure or weld cracked. As can be seen from the strain data and test results, the position of the upper edge of specimen appeared the maximum deformation and first yielded. The joint of the two connections was not damaged under monotonic loading, as shown in Figure 4(a), and the degree of buckling failure of specimens connected by single fish plate connectors was more serious and out-of-plane 
deformation was larger. Specimens connected by single fish plate connectors were damaged because of weld cracked under cyclic loading test, and out-of-plane deformation of SPSWs was large. But the specimens connected by double fish plate connectors only appeared buckling failure, and there were some small cracks appeared near the connectors, as shown in Figure 4(b).

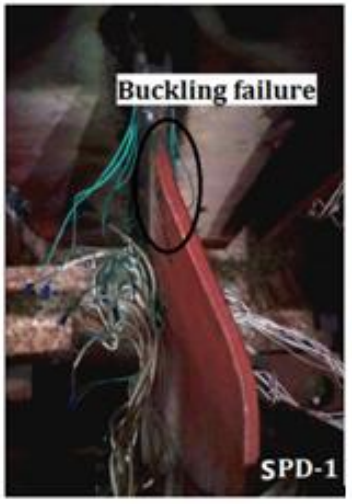

(a) Monotonic loading test

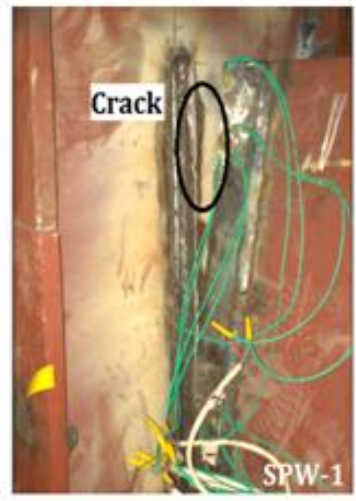

(b) Cyclic loading test

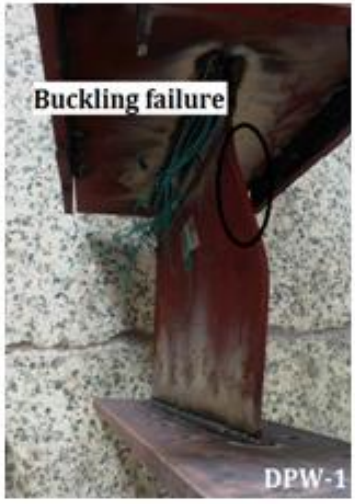

DPW-1

Figure 4. The failure of specimens.

\section{ANALYSIS OF EXPERIMENT RESULT}

\section{Experiment results under monotonic loading}

Two kinds of connections were tested and analyzed under monotonic loading. Experiment results are shown in Table 2. It can be seen from the data that the ultimate bearing capacity of double fish plate connection was higher than single fish plate connection by about $10.9 \%$. When the load reached to ultimate load, specimens connected by single fish plate connectors had lost the capacity of bearing load, while specimens connected by double fish plate connectors could continue to load. Results showed that the behavior of double fish plate connectors was better, which had high bearing capacity and good ductility.

Table 2. Experiment results.

\begin{tabular}{ccccccc}
\hline $\begin{array}{c}\text { Specimen } \\
\text { number }\end{array}$ & $\begin{array}{c}\text { Yield } \\
\text { Load } \\
(\mathrm{kN})\end{array}$ & $\begin{array}{c}\text { Yield } \\
\text { displacement } \\
(\mathrm{mm})\end{array}$ & $\begin{array}{c}\text { Ultimate } \\
\text { load } \\
(\mathrm{kN})\end{array}$ & $\begin{array}{c}\text { Ultimate } \\
\text { displacement } \\
(\mathrm{mm})\end{array}$ & $\begin{array}{c}\text { Failure } \\
\text { load } \\
(\mathrm{kN})\end{array}$ & $\begin{array}{c}\text { Failure } \\
\text { displacement } \\
(\mathrm{mm})\end{array}$ \\
\hline SPD-1 & 651.06 & 12.13 & 997.36 & 19.21 & - & - \\
DPD-1 & 656.2 & 14.61 & 1106.71 & 26.3 & 950.2 & 26.71 \\
\hline
\end{tabular}

\section{Experiment results under cyclic loading}

Hysteretic cures and skeleton curves. The hysteretic curves of single fish plate connection (SPW1) and double fish plate connection (DPW-1) are showed in Figure 5. Skeleton curve of two connections are shown in Figure 6, which reflected the force of different load levels. As shown in Figure 5, the hysteretic curve of DPW-1 is more full than SPW-1, which shows that energy dissipation capacity of SPW-1 was better. During the initiation of loading, the area of hysteresis loop and residual deformation are small, the loading and unloading process are basically 
symmetrical. When the load reached the yielding displacement, the area of hysteresis loop and residual deformation increased, which indicates that the structure began to absorb energy. At the same time, SPW-1 began to appear obviously yielding phenomenon, and this type connection effectively restrained out-of-plane deformation caused by steel plate buckling. As reached the ultimate bearing capacity, stiffness degenerated, bearing capacity decreased, structure deformation increased, then the loading and unloading process were entirely different. Test was not stopped until SPSWs lost bearing capacity. As shown in Figure 6, the ultimate bearing capacity of double fish plate connectors increased $15.67 \%$ than that of single fish plate connectors. The results showed that the crack of specimens connected by single fish plate connectors appeared at the end of test, while the excessive deformation of specimens connected by double fish plate connectors leading to buckling failure caused the end of test. By contrast, the new connection increased the bearing capacity, delayed structural damage.
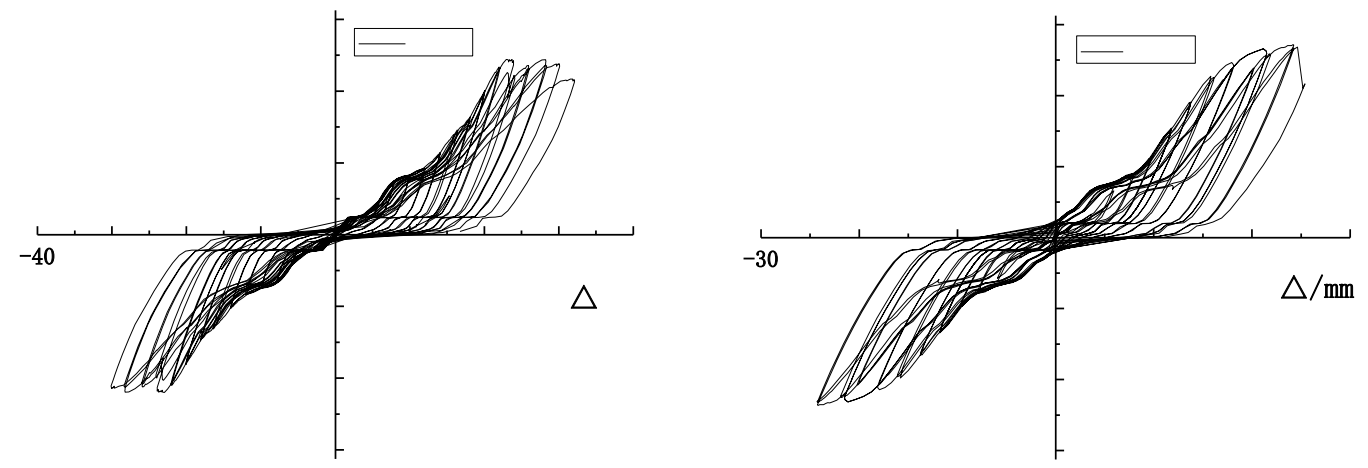

Figure 5. Hysteretic cures of two connections.

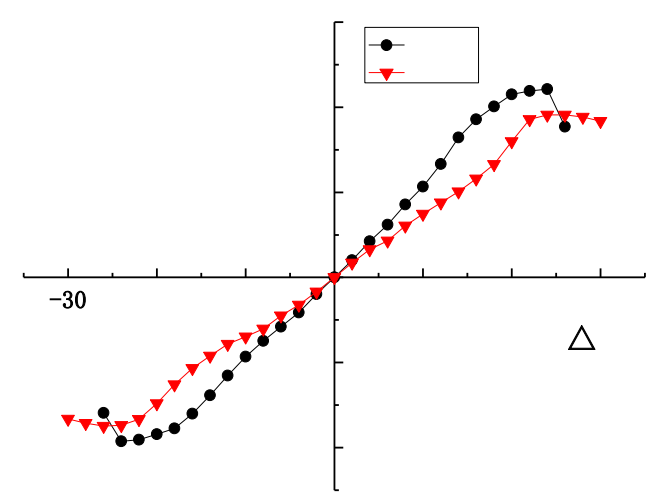

Figure 6. Skeleton curve of two connections.

Stiffness degradation. Stiffness degradation is refered to the phenomenon that stiffness of the structures would decrease under cyclic loading if the times of cyclic loading increased. Usually in order to reflect characteristics of stiffness degradation, using loop stiffness to represent the stiffness degradation of structures under the same level of deformation. The secant stiffness (K) was used to approximately replace loop stiffness. As is shown in Figure 7, stiffness of DPW-1 is 
higher than that of SPW-1. During the entire process of loading, stiffness degradation of both specimens was uniform and stable. However, the loss of stiffness of DPW-1 is $35.89 \%$ and the loss of stiffness of SPW-1 is $55.16 \%$, which shows that the constraint and the cooperative behavior between double fish plate connectors and SPSWs is better.

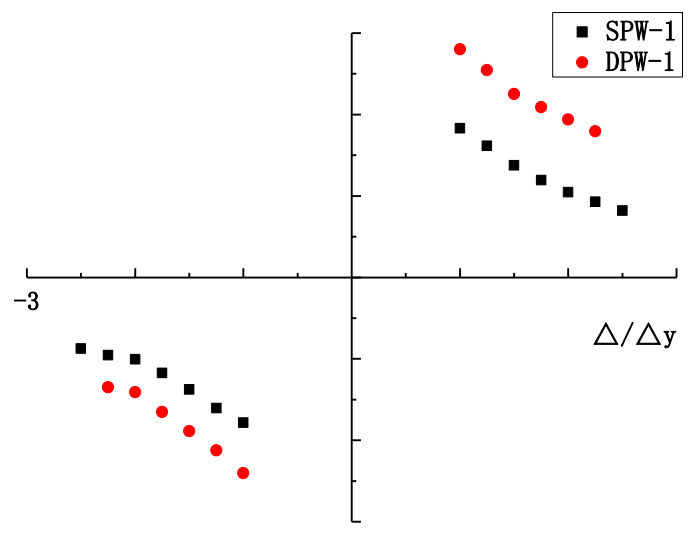

Figure 7. Stiffness degradation curve of two connections.

Ductility coefficient. Ductility is refered to the deformability that bearing capacity has no significant decline after load reached ultimate bearing capacity or exceeded ultimate bearing capacity. Ductility coefficient was used to evaluate the ductility of specimens and defined as the ratio of ultimate displacement and yield displacement. The larger the ductility coefficient is, the better the ductility is. Table 3 shows that ductility coefficient of DPW-1 is 2.29 and ductility coefficient of SPW-1 is 2.06, therefore, the ductility of DPW-1 is better than that of SPW-1.

Table 3. Ductility coefficient.

\begin{tabular}{cccccc}
\hline $\begin{array}{c}\text { Specimens } \\
\text { number }\end{array}$ & $\begin{array}{c}\text { Ultimate } \\
\text { load } \\
(\mathrm{kN})\end{array}$ & $\begin{array}{c}\text { Ultimate } \\
\text { displacement } \\
(\mathrm{mm})\end{array}$ & $\begin{array}{c}\text { Yield } \\
\text { Load } \\
(\mathrm{kN})\end{array}$ & $\begin{array}{c}\text { Yield } \\
\text { displacement } \\
(\mathrm{mm})\end{array}$ & $\begin{array}{c}\text { Ductility } \\
\text { coefficient }\end{array}$ \\
\hline SPW-1 & 955.63 & 26.13 & 439.15 & 12.67 & 2.06 \\
DPW-1 & 1105.43 & 25.45 & 455.67 & 11.07 & 2.29 \\
\hline
\end{tabular}

\section{CONCLUSION}

Based on the test results presented in this paper two preliminary conclusions can be made.

- The ultimate bearing capacity of new type double fish plate connection was higher than ordinary single fish plate connection by about $10.96 \%$ under monotonic loading. The ultimate bearing capacity of double fish plate connections was higher than single fish plate connections by about $15.67 \%$ under cyclic loading. It can be seen from the test results that the bearing capacity of double fish plate connection is higher. 
- The proposed new type double fish plate connection has been shown capable of reducing buckling and exhibited more full hysteretic behavior than ordinary single fish plate connection. Results shows that the specimens connected by double fish plate connectors have better energy dissipation capacity and better ductility.

\section{ACKNOWLEDGEMENTS}

The authors are grateful for the financial support of National Key Technology R\&D Program during the "12th Five-Year Plan" period (2012BAJ13B05).

\section{REFERENCES}

Chen, G. D., and Guo, X. L. (2004). "Ultimate shear-carrying capacity of steel plate shear wall with cross stiffeners." Journal of Building Structures, Vol.25(1), 71-78.

Driver, R. G., Kulak, G. L., Kennedy, D. J. L., and Elwi, A. B. (1998). "Cyclic test of a fourstory steel plate shear wall." Journal of Structural Engineering. ASCE, Vol.124(2), 112-120.

Guo, H. C., Hao, J. P., Pan, X. Z., and Liu, J. J. (2013). "Seismic behavior of four-angleconnection steel frame structure with steel plate shear walls." Journal of Building Structures, Vol.34(1), 70-75.

Guo, Y. L., Dong, Q. L., and Zhou, M. (2009). "Tests and analysis on hysteretic behavior of buckling-restrained steel plate shear wall.” Journal of Building Structures, Vol.30(1), 31-39.

Elgaaly, M., Caccese, V., and Du, C. (1993). "Post-bucking behavior of steel-plate shear walls under cyclic loads." Journal of Structural Engineering, Vol.119(2), 588-605.

Hao, J. P., Guo, H. C., and Xie, Q. (2011). "Seismic performance of composite steel frame with steel plate shear walls." Journal of Building Structures, Vol.31(2), 33-40.

Hitaka, T., and Matsui, C. (2003). "Experimental study on steel shear wall with slits." Journal of Structure Engineering, ASCE, Vol.129(5), 586-595.

Kulak, G. L. (1985). "Behavior of steel plate shear walls." Proceedings, AISC International Engineering Symposium on Structural Steel, Amer. Inst. of Steel Construction, Chicago.

Mauray, A., Egorova, N., and Eatherton, M. R. (2013). "Development of ring-shaped steel plate shear walls." Structures Congress, ASCE, 2971-2982.

Mimura, H., and Akiyama, H. (1997). "Load-deflection relationship of earthquake-resistant steel plate shear walls with a developed diagonal tension field." Trans, Arch. Inst. of Japan, Tokyo, Japan, 109-114.

Roberts, T., and Sabouri-Ghomi, S. (1992). "Hysteretic characteristics of unstiffened perforated steel plate shear panels." Thin Walled Structures, Vol.14, 139-151.

Takahash, T., Takemoto, Y., and Tkeda, T. (1973). "Experimental study on thin steel shear walls and particular bracings under alternative horizontal load." IABSE Symposium. International Association for Bridge and Structural Engineering, Lisbon, Portugal, 185-191.

Thorburn, L. J., Kulak, G. L., and Montgomery, C. J. (1983). "Analysis of steel plate shear walls." Structural Engineering Report No.107. University of Alberta,Canada.

Wang, M., and Yang, W. G. (2015). "Hysteretic behaviors study of thin steel plate shear wall structures." Journal of Building Structures, Vol.36(1), 68-77.

Xie, Q., Hao, J. P., and Yu, J. G. (2010). "Behavior of semi-rigid frame with steel plate shear wall.” Journal of Building Structures, Vol.31(S1), 12-17. 